BMJ Open

Respiratory

Research

\title{
A cohort study to identify simple clinical tests for chronic respiratory failure in obese patients with sleep-disordered breathing
}

\author{
S Mandal, ${ }^{1,2}$ E S Suh, ${ }^{1,2}$ E Boleat, ${ }^{1}$ W Asher, ${ }^{1}$ M Kamalanathan, ${ }^{1} \mathrm{~K}$ Lee, ${ }^{2,3}$ \\ A Douiri, ${ }^{4,5}$ P B Murphy, ${ }^{1,2}$ J Steier, ${ }^{1,2,3}$ N Hart ${ }^{1,2,3,5}$
}

To cite: Mandal S, Suh ES, Boleat E, et al. A cohort study to identify simple clinical tests for chronic respiratory failure in obese patients with sleep-disordered breathing. BMJ Open Resp Res 2014;1 e000022. doi:10.1136/ bmjresp-2014-000022

Received 22 January 2014 Revised 7 March 2014 Accepted 12 March 2014

\section{(a) CrossMark}

${ }^{1}$ Lane Fox Clinical Respiratory Physiology Research Centre, St Thomas' Hospital, Guy's and St Thomas' NHS Foundation Trust, London, UK

${ }^{2}$ Division of Asthma Allergy and Lung Biology, King's College London, London, UK ${ }^{3}$ Lane Fox Respiratory Unit, Guy's and St Thomas' NHS Foundation Trust, London, UK

${ }^{4}$ Division of Health and Social Care Research, King's College London, London, UK

${ }^{5}$ Guy's and St Thomas' NHS Foundation Trust and King's College London, National Institute Health Research Biomedical Research Centre, London, UK

Correspondence to Dr Swapna Mandal; swapnamandal@hotmail.com

\section{ABSTRACT}

Background: Chronic respiratory failure complicating sleep-disordered breathing in obese patients has important adverse clinical implications in terms of morbidity, mortality and healthcare utilisation. Screening strategies are essential to identify obese patients with chronic respiratory failure.

Method: Prospective data were collected from patients with obesity-related sleep-disordered breathing admitted for respiratory assessment at a UK national sleep and ventilation centre. Hypercapnia was defined as an arterial partial pressure of carbon dioxide of $>6 \mathrm{kPa}$.

Results: 245 obese patients ( $56 \pm 13$ years) with a body mass index of $48 \pm 12 \mathrm{~kg} / \mathrm{m}^{2}$, forced vital capacity (FVC) of $2.1 \pm 1.1 \mathrm{~L}$, daytime oximetry $\left(\mathrm{SpO}_{2}\right)$ of $91 \pm 6 \%$ and abnormal overnight oximetry were included in the analysis. Receiver operator curve analysis for the whole group showed that an FVC $\leq 3 \mathrm{~L}$ had a sensitivity of $90 \%$ and a specificity of $41 \%$ in predicting

hypercapnia, and an $\mathrm{SpO}_{2} \leq 95 \%$ had a sensitivity of $83 \%$ and a specificity of $63 \%$ in predicting hypercapnia. Gender differences were observed and receiver operator curve analysis demonstrated 'cut-offs' for (1) $\mathrm{SpO}_{2}$ of $\leq 95 \%$ for men and $\leq 93 \%$ for women and (2) FVC of $\leq 3.5 \mathrm{~L}$ for men and $\leq 2.3 \mathrm{~L}$ for women, in predicting hypercapnia.

Conclusions: The measurement of FVC and clinic $\mathrm{SpO}_{2}$ in obese patients with abnormal overnight limited respiratory studies predicted hypercapnia. This may have clinical utility in stratifying patients attending sleep clinics.

\section{BACKGROUND}

Increasing trends in obesity are well publicised with a worldwide increase in body mass index (BMI) of $0.4 \mathrm{~kg} / \mathrm{m}^{2}$ per annum. ${ }^{1}$ Within the UK, almost a quarter of all adults are currently classified as obese, with an annual cost to the National Health Service (NHS) of $£ 5.1$ billion. $^{2}$ BMI is strongly associated with all-cause mortality, and this imposes an extra significant burden

\section{Key messages}

Simple physiological tools of clinic $\mathrm{SpO}_{2}$ and FVC can be used to predict hypercapnia with high sensitivity, in patients with a BMl $>30 \mathrm{~kg} / \mathrm{m}^{2}$ and evidence of sleep disordered breathing.

- For men an $\mathrm{SpO}_{2}<95 \%$ and $\mathrm{FVC}<3.5 \mathrm{~L}$ is predictive of hypercapnia, for women these cut-offs are $<93 \%$ and $2.3 \mathrm{~L}$.

- This may assist in streamlining the clinical assessment of obese patients with sleep disordered breathing.

on the healthcare system. ${ }^{3-5}$ Over $50 \%$ of patients with a BMI greater than $40 \mathrm{~kg} / \mathrm{m}^{2}$ have obstructive sleep apnoea (OSA), and up to one-third of morbidly obese patients exhibit obesity hypoventilation syndrome. ${ }^{6-8}$ As expected, the patients with chronic hypercapnic respiratory failure have a higher morbidity, mortality and healthcare utilisation compared with non-hypercapnic obese patients with OSA. ${ }^{9-11}$ Given the increasing requirement to provide advanced respiratory technologies, such as continuous positive airway pressure treatment (CPAP) and non-invasive ventilation (NIV) for obesity-related sleep-disordered breathing, ${ }^{12} 13$ it has become a priority for sleep services to develop simple screening tools to predict hypercapnia so that a personalised clinical approach can be applied to the patient.

A common practice in sleep medicine is to use home overnight oximetry monitoring ahead of the first clinic consultation, which aims to streamline the 18-week NHS referral to treatment clinical pathway ${ }^{12}$ and therefore limiting the financial penalties that are incurred by the healthcare providers when pathway breaches occur. To enhance the clinical pathway, it would be desirable to develop a simple respiratory screening strategy to 
reliably identify those high-risk obese patients with oximetry confirmed sleep-disordered breathing who have coexistent chronic respiratory failure so that the appropriate treatment can be initiated promptly. We hypothesised that clinic oxygen saturation $\left(\mathrm{SpO}_{2}\right)$ and forced vital capacity (FVC) would be clinically useful measurements in predicting chronic respiratory failure in obese patients with sleep-disordered breathing.

\section{PATIENTS AND METHODS \\ Study population}

Patients with sleep-disordered breathing admitted to a secondary and tertiary referral sleep and ventilation centre were included in the analysis. All data were gathered prospectively from a bespoke clinical database (CareVue, Philips, USA). All patients were initiated on nocturnal positive airway pressure therapy, including CPAP and NIV, as per the standard unit clinical protocol.

\section{Inclusion and exclusion criteria}

Patients with BMI $>30 \mathrm{~kg} / \mathrm{m}^{2}$ and evidence of sleepdisordered breathing during overnight monitoring were included. Patients with spirometric evidence of obstructive airways disease (forced expiratory volume in $1 \mathrm{~s} / \mathrm{FVC}$ ratio, $\mathrm{FEV}_{1} / \mathrm{FVC}$ ratio $\left.<70 \%\right)$ or evidence of Cheyne-Stokes respiration during nocturnal monitoring were excluded.

\section{Population demographics and physiological measurements}

Arterial blood gas sampling, spirometry and clinic $\mathrm{SpO}_{2}$ measurements were performed with patients in a seated position breathing room air at least $4 \mathrm{~h}$ after waking. Analysis of arterial partial pressure of oxygen $\left(\mathrm{PaO}_{2}\right)$, arterial partial pressure of carbon dioxide $\left(\mathrm{PaCO}_{2}\right)$, arterial bicarbonate concentration $\left(\mathrm{HCO}_{3}^{-}\right)$and $\mathrm{pH}$ were performed using a standard analyser (ABL 90, Radiometer, West Sussex, UK). FEV 1 and FVC were measured using a handheld spirometer (Micromedical, Carefusion Ltd, Germany) according to a standard protocol. ${ }^{14} \mathrm{SpO}_{2}$ was measured using pulse oximetry (Massimo UK, Hants, UK). Daytime somnolence was assessed using the Epworth Sleepiness Score (ESS). ${ }^{15}$ Data from the overnight limited respiratory monitoring (transcutaneous carbon dioxide $\left(\mathrm{TcCO}_{2}\right)$ and $\mathrm{SpO}_{2}$, TOSCA, Radiometer Ltd, Crawley, London) were interpreted by expert physicians as part of an established multidisciplinary meeting. Demographic, anthropometric measurements and data detailing comorbidities (ischaemic heart disease, cerebrovascular disease, diabetes mellitus and systemic hypertension) were sourced from the medical e-records system.

\section{Statistical analysis}

Data analyses were performed using SPSS (V.19, IBM Corporation Ltd, USA). Data are presented as mean \pm SD for parametric data. Data were tested for normality and parametric analyses conducted. Data were analysed across all patients with eucapnia and hypercapnia using independent $\mathrm{t}$ tests. Further analyses were conducted to assess the utility of physiological parameters in predicting $\mathrm{PaCO}_{2}$ level $\geq 6 \mathrm{kPa}$. Relationships between spirometric measurements and gas exchange were investigated using regression analyses. The clinical utility of $\mathrm{SpO}_{2}$ and FVC in predicting hypercapnia was assessed using receiver-operator characteristic (ROC) analyses. For all analyses, $\mathrm{p}$ value $<0.05$ was considered statistically significant.

\section{RESULTS}

\section{Patient diagnoses}

In total, 245 obese patients (130 men, 53\%) were studied between January 2006 and March 2012. In total, $91 \%$ had a BMI $>35 \mathrm{~kg} / \mathrm{m}^{2}, 72 \%$ had a BMI $>40 \mathrm{~kg} / \mathrm{m}^{2}, 51 \%$ had a BMI $>45 \mathrm{~kg} / \mathrm{m}^{2}$ and $34 \%$ had a BMI $>50 \mathrm{~kg} / \mathrm{m}^{2}$. In total, $164(67 \%)$ were hypercapnic, with $\mathrm{PaCO}_{2}$ above $6 \mathrm{kPa}$. Patients with eucapnic OSA had a $4 \%$ oxygen desaturation index (ODI) of 24.5 \pm 19.5 events/h with nocturnal $\mathrm{SpO}_{2}$ of $94.1 \pm 3.2 \%$, and the percentage of analysis time with $\mathrm{SpO}_{2}$ below $90 \%$ was $13.5 \pm 20.4 \%$. In patients with hypercapnia, the $4 \%$ ODI was higher at $42.6 \pm 35.5$ events/h (hypercapnic vs eucapnic group; $\mathrm{p}=0.003$ ), nocturnal $\mathrm{SpO}_{2}$ was lower at $89.0 \pm 7.4 \%$ (hypercapnic vs eucapnic group; $\mathrm{p}=\mathrm{ns}$ ) and the percentage of analysis time with $\mathrm{SpO}_{2}$ below $90 \%$ was higher at $36.3 \pm 32.1 \%$ (hypercapnic vs eucapnic group; $\mathrm{p}<0.001)$.

\section{Clinical outcome data}

There were 12 deaths in the cohort $(6.8 \%)$ during a mean follow-up period of 2.7 years; of these, $9(75 \%)$ were hypercapnic. Non-survivors, compared with survivors, were older ( $65 \pm 10$ years vs $55 \pm 13$ years; $\mathrm{p}=0.006)$, had a longer length of hospital stay during inpatient nocturnal ventilatory support set-up (5.8 \pm 3.0 days vs $3.4 \pm 3.3$ days; $\mathrm{p}=0.02$ ), higher haematocrit $(44.6 \pm 7.1 \%$ vs $40.0 \pm 14.6 \%$; $\mathrm{p}=0.03)$, higher admission $\mathrm{PaCO}_{2}(7.37 \pm 1.15 \mathrm{kPa}$ vs $6.55 \pm 1.12 \mathrm{kPa}$; $\mathrm{p}=0.02)$, lower $\mathrm{FEV}_{1}(1.13 \pm 0.65 \mathrm{~L}$ vs $1.90 \pm 0.99 \mathrm{~L} ; \mathrm{p}=0.008)$ and lower FVC $(1.33 \pm 0.69 \mathrm{~L}$ vs $2.25 \pm 1.13 \mathrm{~L} ; \mathrm{p}<0.006)$. There was a trend for the frequency of diabetes mellitus to be greater in the hypercapnic group compared with the eucapnic group ( $40 \%$ vs $28 \%$; $\mathrm{p}=0.07$ ). There was also a significant difference in $\mathrm{PaCO}_{2}$ between genders (men 6.3 $\pm 1.1 \mathrm{kPa}$ vs women $6.9 \pm 1.1 \mathrm{kPa} ; \mathrm{p}<0.001$ ). Data for each group are shown in table 1 .

\section{Patients with hypercapnia versus eucapnia}

The eucapnic group differed from the hypercapnic group. In particular, the hypercapnic group had significantly lower $\mathrm{FEV}_{1}(2.48 \pm 0.98 \mathrm{~L}$ vs $1.55 \pm 0.84 \mathrm{~L} ; \mathrm{p}<0.001)$, FVC $(2.92 \pm 1.12 \mathrm{~L}$ vs $1.84 \pm 0.97 \mathrm{~L} ; \mathrm{p}<0.001)$, clinic $\mathrm{SpO}_{2}(94.7$ $\pm 2.6 \%$ vs $89.8 \pm 6.1 \% ; \mathrm{p}<0.001)$ and $\mathrm{PaO}_{2}(9.86 \pm 1.49 \mathrm{kPa}$ vs $8.2 \pm 1.37 \mathrm{kPa} ; \mathrm{p}<0.001)$ compared with the patients with 
Table 1 Demographic, anthropometric and comorbidity data across the different groups of sleep-disordered breathing

\begin{tabular}{|c|c|c|}
\hline & Eucapnic $\left(\mathrm{PaCO}_{2}<6 \mathrm{kPa}\right)(\mathrm{n}=83)$ & Hypercapnic $\left(\mathrm{PaCO}_{2} \geq 6 \mathrm{kPa}\right)(\mathrm{n}=162)$ \\
\hline Age (years) & $53 \pm 12$ & $56 \pm 14$ \\
\hline Length of stay (days) & $2 \pm 2$ & $4 \pm 4^{\star}$ \\
\hline BMI $\left(\mathrm{kg} / \mathrm{m}^{2}\right)$ & $44.1 \pm 9.7$ & $50 \pm 12^{*}$ \\
\hline ESS & $14 \pm 6$ & $14 \pm 6$ \\
\hline Clinic $\mathrm{SpO}_{2}(\%)$ & $94.7 \pm 2.6$ & $89.8 \pm 6.1^{*}$ \\
\hline Ischaemic heart disease & $15(18)$ & $26(16)$ \\
\hline Stroke & $3(4)$ & $8(5)$ \\
\hline Diabetes mellitus & $23(28)$ & $64(40)$ \\
\hline Systemic hypertension & $45(54)$ & $91(56)$ \\
\hline
\end{tabular}

eucapnia. As expected, $\mathrm{PaCO}_{2}$ and $\mathrm{HCO}_{3}{ }^{-}$levels were higher in the hypercapnic groups $(5.43 \pm 0.38 \mathrm{kPa}$ vs 7.18 $\pm 0.91 \mathrm{kPa} ; \mathrm{p}<0.001$ and $25.5 \pm 1.9$ vs31.8 $\pm 3.6 \mathrm{mmol} / \mathrm{L}$; $\mathrm{p}<0.001$, respectively, table 2 ).

\section{Relationships between gas exchange, body composition and lung volume at different levels of BVII}

There were weak correlations observed across the whole cohort between clinic $\mathrm{SpO}_{2}$ and FVC $(\mathrm{r}=+0.43, \mathrm{p}<0.001)$ and $\%$ predicted FVC $(\mathrm{r}=+0.23, \mathrm{p}<0.001)$. There were also weak correlations between BMI and clinic $\mathrm{SpO}_{2}(\mathrm{r}=$ $-0.22, \mathrm{p}=0.001)$, and between $\mathrm{BMI}$ and $\mathrm{PaCO}_{2}(\mathrm{r}=+0.25$, $\mathrm{p}<0.001)$. As expected, there were inverse correlations observed between $\mathrm{PaCO}_{2}$ and $\mathrm{SpO}_{2}(\mathrm{r}=-0.56, \mathrm{p}<0.001)$, and between $\mathrm{PaCO}_{2}$ and FVC $(\mathrm{r}=-0.53, \mathrm{p}<0.001)$, but the relationship between $\mathrm{PaCO}_{2}$ and \% predicted FVC was again weak $(\mathrm{r}=-0.32, \quad \mathrm{p}<0.001)$. These weak

Table 2 Spirometric and arterial blood gas measurements

\begin{tabular}{|c|c|c|}
\hline & $\begin{array}{l}\text { Eucapnic } \\
(n=83)\end{array}$ & $\begin{array}{l}\text { Hypercapnic } \\
(n=162)\end{array}$ \\
\hline $\mathrm{FEV}_{1}(\mathrm{~L})$ & $2.48 \pm 0.98$ & $1.55 \pm 0.84^{*}$ \\
\hline FVC (L) & $2.92 \pm 1.12$ & $1.84 \pm 0.97^{*}$ \\
\hline $\mathrm{FEV}_{1} / \mathrm{FVC}$ & $0.85 \pm 0.08$ & $0.84 \pm 0.08$ \\
\hline $\begin{array}{l}\mathrm{FEV}_{1} \% \\
\text { predicted }\end{array}$ & $77.6 \pm 23.1$ & $58.5 \pm 44.6^{\star}$ \\
\hline $\begin{array}{l}\text { FVC \% } \\
\text { predicted }\end{array}$ & $74.7 \pm 21.8$ & $56.9 \pm 36.6^{\star}$ \\
\hline $\mathrm{pH}$ & $7.41 \pm 0.02$ & $7.39 \pm 0.06^{*}$ \\
\hline $\mathrm{PaO}_{2}(\mathrm{kPa})$ & $9.86 \pm 1.49$ & $8.15 \pm 1.36^{*}$ \\
\hline $\mathrm{PaCO}_{2}(\mathrm{kPa})$ & $5.43 \pm 0.38$ & $7.19 \pm 0.9^{*}$ \\
\hline $\mathrm{HCO}_{3}^{-}\left(\mathrm{mmol} / \mathrm{L}^{1}\right)$ & $25.5 \pm 1.9$ & $31.8 \pm 3.6^{*}$ \\
\hline Base excess & $1.0 \pm 1.7$ & $5.96 \pm 4.17^{\star}$ \\
\hline Haematocrit (\%) & $44.0 \pm 5.0$ & $44.4 \pm 8.7$ \\
\hline \multicolumn{3}{|c|}{$\begin{array}{l}\text { Values expressed as mean } \pm \mathrm{SD} \text {. } \\
\left.{ }^{*} \text { Significant difference compared with eucapnic group ( } \mathrm{p}<0.001\right) \text {. } \\
\mathrm{FEV}_{1} \text {, forced expiratory volume in } 1 \mathrm{~s} ; \mathrm{FVC} \text {, forced vital capacity; } \\
\mathrm{HCO}_{3}^{-} \text {, arterial bicarbonate ion concentration; } \mathrm{PaCO}_{2} \text {, arterial } \\
\text { partial pressure of carbon dioxide; } \mathrm{PaO}_{2} \text {, arterial partial pressure } \\
\text { of oxygen. }\end{array}$} \\
\hline
\end{tabular}

relationships were maintained when the patients were grouped according to BMI (tables 3 and 4).

\section{Clinic $\mathrm{SpO}_{2}$ and FVC to predict hypercapnia}

Multiple linear regression was performed using all the variables for which the bivariate correlation with $\mathrm{PaCO}_{2}$ was significant. These variables were used then to identify the physiological variables that predicted $\mathrm{PaCO}_{2}>6 \mathrm{kPa}$. Clinic $\mathrm{SpO}_{2}$ and $\mathrm{FVC}$ were retained in the linear model and stepwise logistic regression was subsequently performed. Clinic $\mathrm{SpO}_{2}$ (OR 0.55, 95\% CI 0.40 to 0.75 ) and FVC (OR 0.76, CI 0.67 to 0.85 ) were retained in the logistic regression model as predictors of hypercapnia. The utility of $\mathrm{SpO}_{2}$ and FVC in predicting hypercapnia was assessed using ROC analyses. For patients with a BMI $>30 \mathrm{~kg} / \mathrm{m}^{2}$ and a 'cut-off' level for clinic $\mathrm{SpO}_{2}$ of $<95 \%$, the area under the curve (AUC) was 0.80 with a sensitivity of $83 \%$ and a specificity of 63\% ( $p<0.001)$. A 'cut-off' level for FVC of $<3 \mathrm{~L}$ had an AUC of 0.79 with a sensitivity of $90 \%$ and a specificity of $41 \%$ in predicting hypercapnia $(\mathrm{p}<0.001)$. The positive predictive value (PPV) of FVC $<3 \mathrm{~L}$ was $65 \%$ with a negative predictive value (NPV) of $95 \%$. For $\mathrm{SpO}_{2}$, the PPV was $34 \%$ and the NPV 94\%. Using lower cut-off levels improved the specificity but with a marked reduction in sensitivity (table 5); however, using sensitivities of above $80 \%$ allows for a low false negative rate of less than $20 \%$. Based on the logistic regression model described above, the combination of $\mathrm{SpO}_{2}$ and FVC for patients with a BMI $>30 \mathrm{~kg} / \mathrm{m}^{2}$ with evidence of sleep-disordered breathing yielded an AUC of 0.83 in predicting hypercapnia (figure 1). Using the bootstrap cross validation method, a combined cut-off level of $\mathrm{SpO}_{2}$ of $<93 \%$ along with FVC $<2.0 \mathrm{~L}$ (AUC 0.83 , CI 0.78 to 0.88 ) can be used to predict hypercapnia with a sensitivity of $53 \%$ (CI $45 \%$ to $60 \%$ ) and specificity of $92 \%$ (CI $83 \%$ to $97 \%$, positive likelihood ratio 6 CI 3 to 13 , negative likelihood ratio 0.5 CI 0.4 to 0.6 ). Finally, and most importantly, we observed that from independent male and female ROC analyses, the cut-off levels for $\mathrm{SpO}_{2}$ and $\mathrm{FVC}$ were $<95 \%$ (AUC 0,73 , CI 0.64 to 0.82 ) and $<93 \%$ (AUC 0.84 , CI 0.76 to 0.93 ), and $3.5 \mathrm{~L}$ (AUC 0.75 , CI 0.66 and 0.83 ) and $<2.3 \mathrm{~L}$ (AUC 0.75 , CI 0.62 to 0.87 ), respectively (table 6 and figure 2 ). 
Table 3 Relationships between $\mathrm{SpO}_{2}$ and daytime $\mathrm{PaCO}_{2}$, body composition and lung volume at different levels of $\mathrm{BMI}$

\begin{tabular}{|c|c|c|c|c|c|c|c|}
\hline & & \multicolumn{2}{|c|}{$\begin{array}{l}\mathrm{BMl}>30 \mathrm{~kg} / \mathrm{m}^{2} \\
\mathrm{n}=245\end{array}$} & \multicolumn{2}{|c|}{$\begin{array}{l}\mathrm{BMl}>40 \mathrm{~kg} / \mathrm{m}^{2} \\
\mathrm{n}=176\end{array}$} & \multicolumn{2}{|c|}{$\begin{array}{l}\mathrm{BMI}>50 \mathrm{~kg} / \mathrm{m}^{2} \\
\mathrm{n}=84\end{array}$} \\
\hline & & $\bar{r}$ & p Value & $\bar{r}$ & p Value & $\bar{r}$ & p Value \\
\hline Correlation with clinic $\mathrm{SpO}_{2}$ & $\begin{array}{l}\mathrm{BMI} \\
\mathrm{PaCO}_{2} \\
\mathrm{FVC}\end{array}$ & $\begin{array}{r}-0.219 \\
-0.555 \\
0.429\end{array}$ & $\begin{array}{r}0.001 \\
<0.001 \\
<0.001\end{array}$ & $\begin{array}{r}-0.16 \\
-0.487 \\
0.374\end{array}$ & $\begin{array}{r}0.034 \\
<0.001 \\
<0.001\end{array}$ & $\begin{array}{r}-0.07 \\
-0.426 \\
0.367\end{array}$ & $\begin{array}{r}0.528 \\
<0.001 \\
0.001\end{array}$ \\
\hline
\end{tabular}

$\mathrm{BMI}$, body mass index; FVC, forced vital capacity; $\mathrm{PaCO}_{2}$, arterial partial pressure of carbon dioxide; $\mathrm{SpO}_{2}$, oxygen saturation.

\section{DISCUSSION}

In this prospective observational cohort study, we have demonstrated that simple spirometric measurements of lung volume and clinic $\mathrm{SpO}_{2}$ predict chronic respiratory failure in obese patients with sleep-disordered breathing. We have also shown, as expected, gender differences for predicting hypercapnic respiratory failure. Surprisingly, previous data have only shown weak correlations between body composition, lung volume and chronic respiratory failure. ${ }^{16} 17$ However, these studies have not considered the clinical physiological predictive power of utilising FVC and daytime clinic oxygen levels $\left(\mathrm{SpO}_{2}\right)$ in obese patients with confirmed evidence of sleepdisordered breathing to enhance screening for chronic respiratory failure. Indeed, we considered that this is a major caveat of the previous studies, and this is the first study to have shown in a large group of obese patients that a clinic $\mathrm{SpO}_{2}$ level below $95 \%$ for a man and $93 \%$ for a woman and an FVC less than 3.5 L for a man and 2.3 L for a woman has high sensitivity to detect hypercapnia, albeit with low specificity. Such tests with a high NPV will ensure that few patients with hypercapnia are missed, albeit at the expense of arterial blood gas measurements being performed on a few patients with eucapnia.

\section{Critique of the method}

These data were collected from a single centre specialising in the management of patients with sleepdisordered breathing and chronic respiratory failure. Although this was a selected cohort of obese patients with sleep-disordered breathing, unlike previous studies, ${ }^{18}$ the current study has identified that the simple clinical tests of FVC and $\mathrm{SpO}_{2}$ are not only reduced in patients with chronic respiratory failure, but also FVG and $\mathrm{SpO}_{2}$ can predict hypercapnic respiratory failure. From the current study, all the patients had sleep-disordered breathing, and it is the presence of a restricted lung volume that identifies the patients with chronic respiratory failure. Although the important associations that we have observed do not necessarily imply a causal link between anthropometric parameters, spirometric parameters and hypercapnic respiratory failure in obese patients, the results are physiologically coherent. The simplest method to test this as a causal mechanism between gas exchange, body composition, sleep-disordered breathing and lung volumes would be to undertake detailed measurements of respiratory polysomnography, pulmonary mechanics and lung volumes before and after significant weight loss, such as prebariatric and postbariatric surgery. $^{19} 20$

Although it is well-recognised that vasoconstriction, dark skin and body movements influence transcutaneous oxygen and carbon dioxide measurements, ${ }^{21}{ }^{22}$ all the physiological measurements were taken according to international and local guidelines and repeated in line with these standards. ${ }^{1423}$ A simple screening tool based on absolute, rather than \% predicted FVC values, would maximise the distribution and application of the test, obviating the need for calculating the \% predicted FVC. Therefore, \% predicted FVC was not included in the multiple linear regression model and absolute FVC measurements were used instead. As expected, gender differences in height would have affected absolute lung volume measurements, but we developed absolute 'cut-offs' for $\mathrm{SpO}_{2}$ and FVG that predict hypercapnia in men and women, respectively. This simple approach to screening would facilitate the incorporation of absolute FVC measurement into clinical practice.

Table 4 Relationships between daytime $\mathrm{PaCO}_{2}$ and clinic $\mathrm{SpO}_{2}$, body composition and lung volume at different levels of BMI

\begin{tabular}{|c|c|c|c|c|c|c|c|}
\hline & & \multicolumn{2}{|c|}{$\begin{array}{l}\mathrm{BMl}>30 \mathrm{~kg} / \mathrm{m}^{2} \\
\mathrm{n}=245\end{array}$} & \multicolumn{2}{|c|}{$\begin{array}{l}\mathrm{BMI}>40 \mathrm{~kg} / \mathrm{m}^{2} \\
\mathrm{n}=176\end{array}$} & \multicolumn{2}{|c|}{$\begin{array}{l}\mathrm{BMl}>50 \mathrm{~kg} / \mathrm{m}^{2} \\
\mathrm{n}=84\end{array}$} \\
\hline & & $\bar{R}$ & p Value & $\bar{R}$ & p Value & $\bar{R}$ & p Value \\
\hline Correlation with $\mathrm{PaCO}_{2}$ & $\begin{array}{c}\mathrm{BMI}\left(\mathrm{kg} / \mathrm{m}^{2}\right) \\
\mathrm{SpO}_{2}(\%) \\
\mathrm{FVC}\end{array}$ & $\begin{array}{r}0.254 \\
-0.555 \\
-0.429\end{array}$ & $\begin{array}{r}0.005 \\
<0.001 \\
<0.001\end{array}$ & $\begin{array}{r}0.218 \\
-0.487 \\
-0.487\end{array}$ & $\begin{array}{r}0.004 \\
<0.001 \\
<0.001\end{array}$ & $\begin{array}{r}0.351 \\
-0.426 \\
-0.472\end{array}$ & $\begin{array}{r}0.001 \\
<0.001 \\
<0.001\end{array}$ \\
\hline
\end{tabular}

$\mathrm{BMI}$, body mass index; FVC, forced vital capacity; $\mathrm{PaCO}_{2}$, arterial partial pressure of carbon dioxide; $\mathrm{SpO}_{2}$, oxygen saturation. 
Table 5 Receiver operator curve analyses for predicting hypercapnia: sensitivity and specificity ranges for differing cut-off levels

\begin{tabular}{lll}
\hline $\begin{array}{l}\text { Cut-off } \\
\text { level }\end{array}$ & $\begin{array}{l}\text { Sensitivity (\%, 95\% } \\
\text { Cl) }\end{array}$ & $\begin{array}{l}\text { Specificity (\%, 95\% } \\
\text { Cl) }\end{array}$ \\
\hline $\begin{array}{lll}\mathrm{SpO}_{2} & & \\
<95 \% & 83(76 \text { to } 88) & 63(51 \text { to } 73) \\
<93 \% & 62(54 \text { to } 70) & 75(65 \text { to } 85) \\
<92 \% & 53(45 \text { to } 61) & 86(76 \text { to } 92)\end{array}$ \\
$\begin{array}{lll}\mathrm{FVC} & & 60(50 \text { to } 71) \\
<2.5 \mathrm{~L} & 80(73 \text { to } 86) & 51(39 \text { to } 62) \\
<2.8 \mathrm{~L} & 88(82 \text { to } 92) & 41(30 \text { to } 52) \\
<3.0 \mathrm{~L} & 90(84 \text { to } 94) & 40(29 \text { to } 51) \\
<3.1 \mathrm{~L} & 90(85 \text { to } 94) & 24(15 \text { to } 35) \\
<3.6 \mathrm{~L} & 96(91 \text { to } 98) & \end{array}$ \\
\hline FVC, forced vital capacity; $\mathrm{SpO}_{2}$, oxygen saturations.
\end{tabular}

\section{Differences between patients with hypercapnia and eucapnia}

To our knowledge, this is the largest UK dataset comparing patients with eucapnia and hypercapnia with sleepdisordered breathing. Interestingly, patients with eucapnia and hypercapnia had similar levels of daytime somnolence demonstrating that the standard clinical assessment, using the $\mathrm{ESS}^{15}$ does not discriminate between those patients with and without chronic respiratory failure. However, as expected, the clinic $\mathrm{SpO}_{2}$ and $\mathrm{PaO}_{2}$ were lower in the hypercapnic group and $\mathrm{SpO}_{2}$ time below $90 \%$ higher, and the relationships between these variables were consistent with previous reports. ${ }^{6} 24$ The patients with chronic respiratory failure had a longer length of stay for establishment of nocturnal respiratory support than those with eucapnia, as a consequence of the extended titration of nocturnal NIV compared with CPAP, which is more straightforward and often can be performed on an outpatient basis. ${ }^{25}$

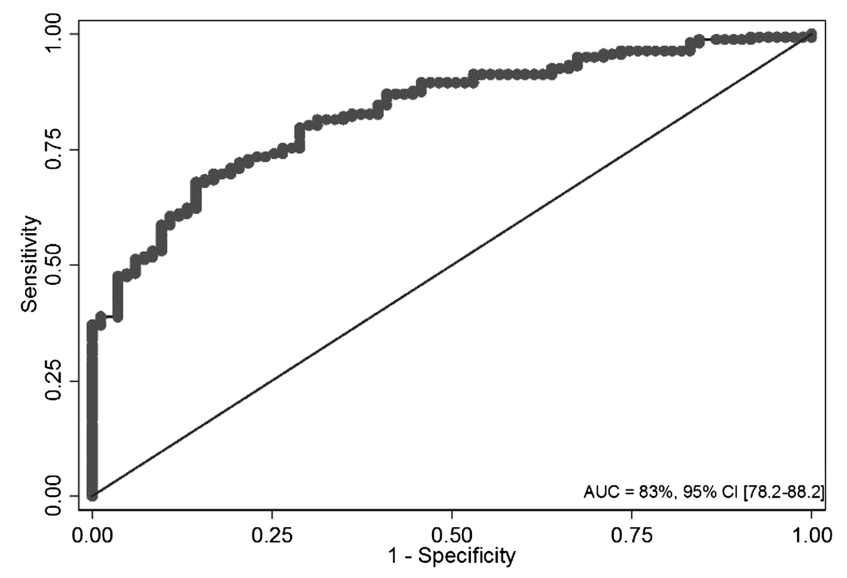

Figure 1 Receiver operator curves for clinic oxygen saturation and forced vital capacity to predict hypercapnia (men and women combined). AUC, area under the curve.
Table 6 Receiver operator curve analyses for predicting hypercapnia: sensitivity and specificity ranges for men and women

\begin{tabular}{llll}
\hline & $\begin{array}{l}\text { Cut-off } \\
\text { level }\end{array}$ & Sensitivity & Specificity \\
\hline All $\mathrm{SpO}_{2}$ & $<95 \%$ & $83(76$ to 88$)$ & $63(51$ to 73$)$ \\
All $\mathrm{FVC}$ & $<3.0 \mathrm{~L}$ & $90(84$ to 94$)$ & $41(30$ to 52$)$ \\
$\mathrm{Men} \mathrm{SpO}_{2}$ & $<95 \%$ & $76(65$ to 85$)$ & $64(51$ to 76$)$ \\
$\mathrm{Men} \mathrm{FVC}$ & $<3.5 \mathrm{~L}$ & $85(74$ to 92$)$ & $29(18$ to 42$)$ \\
Women & $<93 \%$ & $74(63$ to 82$)$ & $63(41$ to 81$)$ \\
$\mathrm{SpO}_{2}$ & & & \\
Women & $<2.3 \mathrm{~L}$ & $99(94$ to 100$)$ & $17(5$ to 37$)$ \\
FVC & & & \\
\hline FVC, forced vital capacity; $\mathrm{SpO}_{2}$, oxygen saturations.
\end{tabular}

\section{Relationship between daytime gas exchange, body composition and lung volume}

In patients with sleep-disordered breathing, univariate analysis demonstrated that clinic $\mathrm{SpO}_{2}$ was correlated, albeit weakly, with BMI, FVC and $\mathrm{PaCO}_{2}$. In addition, $\mathrm{PaCO}_{2}$ was weakly correlated with BMI and FVC. These data provide support for the evidence of these weak direct and inverse associations between body composition, lung volume and hypercapnia. More importantly, multivariate linear regression analysis demonstrated that $\mathrm{FVC}$ and $\mathrm{SpO}_{2}$ were retained in the model predicting hypercapnia, and the ROC analysis demonstrated that FVC and $\mathrm{SpO}_{2}$ had sufficient sensitivity to be clinically useful predictors of chronic respiratory failure, albeit the specificity was low. These data have shown that an abnormal overnight oximetry study combined with a clinic $\mathrm{SpO}_{2}$ and an FVC measurement could be used as part of a sleep screening programme. The rationale for any future study would be to predict hypercapnic respiratory failure by employing a sleep screening strategy of overnight home oximetry to identify patients with sleep-disordered breathing combined with an FVC and a clinic $\mathrm{SpO}_{2}$ cut-off level. A clinically relevant primary event-related outcome in terms of health service research would be time to diagnose and treat hypercapnic respiratory failure with, secondary end-points including cost utility analysis and patient satisfaction.

\section{Clinical implications}

With the increasing incidence of obesity, general practitioners, as well as respiratory sleep clinics, have to be fully cognisant of the respiratory effects of obesity, including patients presenting with chronic respiratory failure. Such patients need to be established on NIV and potential delays and clinical pathway breaches will occur unless a streamlined system is in operation. A number of units already dispatch, via a courier and postal service, an oximeter prior to the clinic appointments. ${ }^{12}$ In those in whom nocturnal oximetry is available, the addition of simple $\mathrm{SpO}_{2}$ and FVC measurements can be performed by ancillary staff; the clinician can stratify those who would require an arterial blood gas to confirm chronic respiratory failure or can be used as additional verification for borderline oximetry results. Although arterial blood gas 
Figure 2 (A) Receiver operator curves for clinic oxygen saturation to predict hypercapnia separated by gender, men (right) and women (left). (B) Receiver operator curves for forced vital capacity to predict hypercapnia separated by gender, men (right) and women (left). ROC, receiver-operator characteristic.
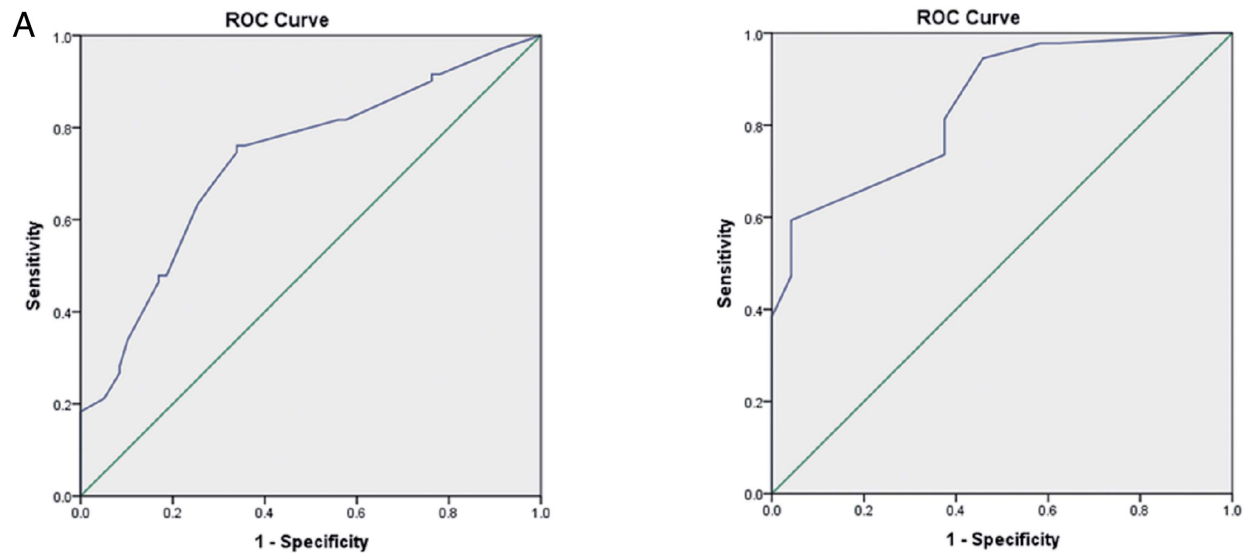

B
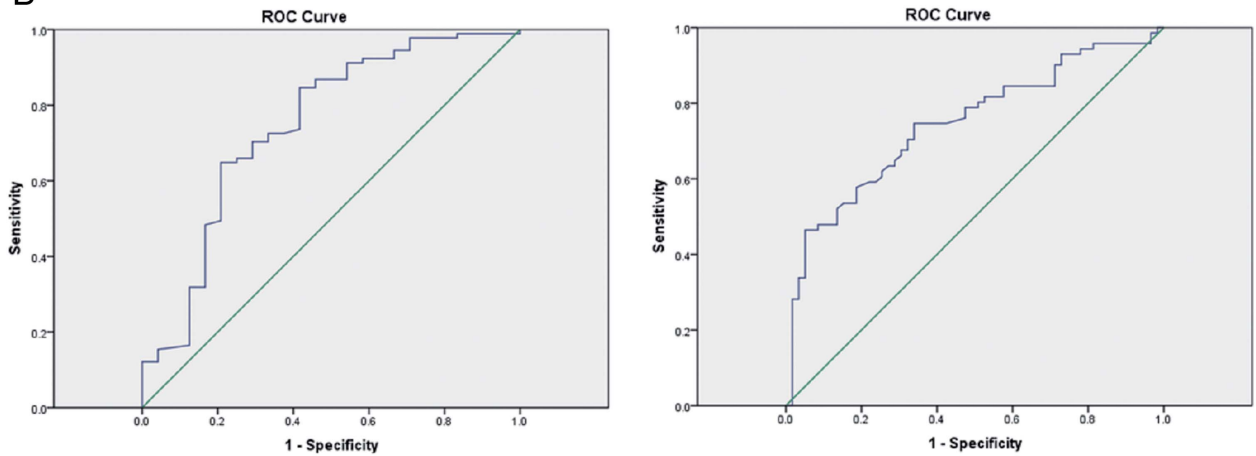

measurement and analysis is a relatively straightforward physiological test to perform, it is painful for the patient, requires skill of the clinician to perform and access to costly analysis equipment, which may not be available in all clinic settings. By using simple non-invasive screening tests of FVC and clinic $\mathrm{SpO}_{2}$, hypercapnia can be predicted in obese patients with sleep-disordered breathing prior the clinic appointment and arrangements made for arterial blood gas sampling to be performed either prior to or during a clinic attendance. This would not only limit the number of patients undergoing arterial blood gas measurements, which would clinically benefit the patient and financially benefit the service, but also ensure the most appropriate treatment is delivered to the patient in a timely fashion.

\section{CONCLUSION}

In conclusion, these novel data demonstrated that absolute FVC and daytime clinic $\mathrm{SpO}_{2}$ in obese patients with sleepdisordered breathing can be used as a screening strategy to predict chronic hypercapnic respiratory failure. An FVC of less than $3.5 \mathrm{~L}$ in a man and $2.3 \mathrm{~L}$ in a woman and a daytime $\mathrm{SpO}_{2}$ below $95 \%$ for a man and $93 \%$ for a woman has a high sensitivity to predict chronic respiratory failure. These tests have the potential to significantly streamline the management of obese patients with oximetry diagnosed sleepdisordered breathing.

Acknowledgements $\mathrm{AD}$ and $\mathrm{NH}$ acknowledge the support by the National Institute for Health Research (NIHR) Clinical Research Facility at Guy's and St Thomas' National Health Service (NHS) Foundation Trust and NIHR
Biomedical Research Centre based at Guy's and St Thomas' NHS Foundation Trust and King's College London.

Contributors SM, ESS, EB, MK and KL were responsible for data collection, analyses and writing the manuscript. $A D$ assisted with statistical analyses. PBM, JS and NH were involved with manuscript preparation.

Funding This research received no specific grant from any funding agency in the public, commercial or not-for-profit sectors.

Competing interests None.

Provenance and peer review Not commissioned; externally peer reviewed.

Data sharing statement No additional data are available.

Open Access This is an Open Access article distributed in accordance with the Creative Commons Attribution Non Commercial (CC BY-NC 3.0) license, which permits others to distribute, remix, adapt, build upon this work noncommercially, and license their derivative works on different terms, provided the original work is properly cited and the use is non-commercial. See: http:// creativecommons.org/licenses/by-nc/3.0/

\section{REFERENCES}

1. Finucane MM, Stevens GA, Cowan MJ, et al. National, regional, and global trends in body-mass index since 1980: systematic analysis of health examination surveys and epidemiological studies with 960 country-years and 9.1 million participants. Lancet 2011;377:557-67.

2. Health Do. Healthy lives, healthy people: a call to action on obesity in England. 2011.

3. Flegal KM, Kit BK, Orpana $\mathrm{H}$, et al. Association of all-cause mortality with overweight and obesity using standard body mass index categories: a systematic review and meta-analysis. JAMA 2013;309:71-82.

4. Wang YC, McPherson $\mathrm{K}$, Marsh $\mathrm{T}$, et al. Health and economic burden of the projected obesity trends in the USA and the UK. Lancet 2011;378:815-25.

5. [No authors listed]. Urgently needed: a framework convention for obesity control. Lancet 2011;378:741.

6. Mokhlesi B, Tulaimat A, Faibussowitsch I, et al. Obesity hypoventilation syndrome: prevalence and predictors in patients with obstructive sleep apnea. Sleep Breath 2007;11:117-24. 
7. Young T, Peppard PE, Taheri S. Excess weight and sleep-disordered breathing. J Appl Physiol 2005;99:1592-9.

8. Jordan AS, McSharry DG, Malhotra A. Adult obstructive sleep apnoea. Lancet 2014;383:736-47.

9. Nowbar S, Burkart KM, Gonzales R, et al. Obesity-associated hypoventilation in hospitalized patients: prevalence, effects, and outcome. Am J Med 2004;116:1-7.

10. Berg G, Delaive K, Manfreda J, et al. The use of health-care resources in obesity-hypoventilation syndrome. Chest 2001;120:377-83.

11. Brillante R, Laks L, Cossa G, et al. An overnight increase in $\mathrm{CO} 2$ predicts mortality in sleep disordered breathing. Respirology 2012;17:933-9.

12. Mandal S, Suh E, Davies M, et al. Provision of home mechanical ventilation and sleep services for England survey. Thorax 2013;68:880-1.

13. Pepperell JC, Ramdassingh-Dow S, Crosthwaite N, et al. Ambulatory blood pressure after therapeutic and subtherapeutic nasal continuous positive airway pressure for obstructive sleep apnoea: a randomised parallel trial. Lancet 2002;359:204-10.

14. Miller MR, Hankinson J, Brusasco V, et al. Standardisation of spirometry. Eur Respir J 2005;26:319-38.

15. Johns MW. Daytime sleepiness, snoring, and obstructive sleep apnea. The Epworth Sleepiness Scale. Chest 1993;103:30-6.

16. Laaban JP, Chailleux E. Daytime hypercapnia in adult patients with obstructive sleep apnea syndrome in France, before initiating nocturnal nasal continuous positive airway pressure therapy. Chest 2005;127:710-15.
17. Resta O, Foschino-Barbaro MP, Bonfitto $\mathrm{P}$, et al. Prevalence and mechanisms of diurnal hypercapnia in a sample of morbidly obese subjects with obstructive sleep apnoea. Respir Med 2000; 94:240-6.

18. Kaw R, Hernandez AV, Walker E, et al. Determinants of hypercapnia in obese patients with obstructive sleep apnea: a systematic review and metaanalysis of cohort studies. Chest 2009;136:787-96.

19. Souza S, Faintuch J, Cecconello I. Spirometric function improves in the morbidly obese after 1-year post-surgery. Obes Surg 2010;20:1273-7.

20. Piper AJ, Grunstein RR. Obesity hypoventilation syndrome: mechanisms and management. Am J Respir Crit Care Med 2011;183:292-8.

21. Mardirossian G, Schneider RE. Limitations of pulse oximetry. Anesth Prog 1992;39:194-6.

22. Feiner JR, Severinghaus JW, Bickler PE. Dark skin decreases the accuracy of pulse oximeters at low oxygen saturation: the effects of oximeter probe type and gender. Anesth Analg 2007;105(6 Suppl): S18-23, tables of contents.

23. [No authors listed]. AARC (American Association for Respiratory Care) clinical practice guideline. Spirometry. Respir Care 1991;36:1414-17.

24. Kessler R, Chaouat A, Schinkewitch P, et al. The obesity-hypoventilation syndrome revisited: a prospective study of 34 consecutive cases. Chest 2001;120:369-76.

25. Stradling JR, Hardinge M, Smith DM. A novel, simplified approach to starting nasal CPAP therapy in OSA. Respir Med 2004:98:155-8. 


\section{Correction}

Mandal S, Suh ES, Boleat E, et al. A cohort study to identify simple clinical tests for chronic respiratory failure in obese patients with sleep-disordered breathing. BMJ Open Resp Res 2014;1:e000022. doi:10.1136/bmjresp-2014-000022

The heading has changed from 'Respiratory research' to 'Sleep disordered breathing and respiratory failure'.

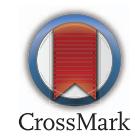

BMJ Open Resp Res 2014;1:e000022corr1. doi:10.1136/bmjresp-2014-000022corr1 